\title{
MOFzyme: Enzyme Mimics of Fe/Fe-MIL-101
}

\author{
Lingli Li1,2, Daomei Chen ${ }^{2,3}{ }^{*}$, Bin $\mathrm{Li}^{2 *}$, Dongqi Yang2 ${ }^{2}$ Jingchen Zhao',3, Danhua Ma1,2, Liang Jiang ${ }^{1,3}$, \\ Yepeng Yang1,3, Yizhou Li1,3, Jiaqiang Wang1,2,3
}

\author{
${ }^{1}$ School of Chemical Sciences \& Technology, Yunnan University, Kunming, China \\ ${ }^{2}$ Key Laboratory of Medicinal Chemistry for Natural Resource, Ministry of Education, Yunnan University, \\ Kunming, China \\ ${ }^{3}$ National Center for International Research on Photoelectric and Energy Materials, Yunnan Province Engineering Research \\ Center of Photocatalytic Treatment of Industrial Wastewater, Yunnan University, Kunming, China \\ Email: *310370301@qq.com, *1ibin36@ynu.edu.cn
}

How to cite this paper: Li, L.L., Chen, D.M., Li, B., Yang, D.Q., Zhao, J.C., Ma, D.H., Jiang, L., Yang, Y.P., Li, Y.Z. and Wang, J.Q. (2019) MOFzyme: Enzyme Mimics of Fe/Fe-MIL-101. Journal of Biosciences and Medicines, 7, 213-221.

https://doi.org/10.4236/jbm.2019.75023

Received: May 10, 2019

Accepted: May 28, 2019

Published: May 31, 2019

\begin{abstract}
In this work, metal-organic frameworks (MOFs) Fe-MIL-101 was synthesized by hydrothermal method, and Fe/Fe-MIL-101 with different loadings was prepared. The crystal structure of the Fe/Fe-MIL-101 sample was characterized by scanning electron microscopy (SEM), X-ray diffraction (XRD) and specific surface area measurement (BET). Fe/Fe-MIL-101 was found to posses an intrinsic enzyme mimicking activity similar to that found in natural horseradish peroxidase (HRP). The Michaelis constant $\left(K_{m}\right)$ of $5 \%$ $\mathrm{Fe} / \mathrm{Fe}$-MIL-101 with ABTS as the substrate is about 10-fold smaller than Fe-MIL-101 and about 3-fold smaller than HRP, and about 108 times less than that of CuO NPs $\left(K_{m}=10.28 \mathrm{mM}\right)$, indicating a much higher affinity for ABTS than HRP and most of the peroxidase mimetics.
\end{abstract}

\section{Keywords}

Metal-Organic Frameworks (MOFs), Fe-MIL-101, 5\% Fe/Fe-MIL-101, Peroxidase Mimetics

\section{Introduction}

Natural enzymes have attracted much attention because of their high catalytic efficiency and strong response characteristics. However, natural enzymes have many problems such as inactivation and denaturation, difficulty in purification, high cost and difficulty in storage and easily affected by environmental conditions including $\mathrm{pH}$, temperature and inhibitors [1] [2]. These defects largely limit the application of enzyme. Therefore, the preparation and application of artificial mimic enzymes is a current research topic in recent years. In the past few decades, many mimic enzymes have been discovered [3] [4], for example, 
cytochrome P450 mimetics [5], serine proteases mimetics [6], dioxygenase mimetics [7], phosphodiesterase mimetics [8] and so on. Among these, a large number of peroxidase mimics, such as hemin [9] [10], hemeatin [11], hemoglobin [12], cyclodextrin [13], and porphyrin [14] [15], etc, have been used for $\mathrm{H}_{2} \mathrm{O}_{2}$ and ascorbic acid detection [13] [14]. However, these peroxide mimic enzymes have lower catalytic activity and poorer selectivity than natural enzymes. Therefore, it is necessary to work harder to design a mimetic enzyme with high catalytic activity.

Metal-organic frameworks (MOFs) are topologically formed by organic ligands and inorganic metal clusters, a type of zeolite-like crystalline porous materials, have been recently researched as new functional materials. Compared with traditional zeolite, activated carbon and other materials, it has the advantages of high specific surface area, adjustable pore structure and easy modification. It has extensively application prospects in the fields of gas storage [16], separation [17] and catalysis [18], and has attracted much attention in science and biological systems. In view of the above advantages of MOFs, we consider it to be a material suitable for simulating enzymes. Indeed, Fe-MIL-101 [19], Fe-MIL-88 $\mathrm{NH}_{2}$ [20], MIL-53(Fe) [21], MIL-100(Fe) and MIL-68(Fe) [22] were found to have the activity of peroxide mimicking enzyme. Cu-MOF [23] was synthesized for catalyzing hydrolysis of bovine serum albumin and casein by solvothermal method. Despite the many exciting and convincing developments recently, we believe that the MOF-based catalytic field is still in the development and immature stage. In this work, we make use of the novel properties of 5\% $\mathrm{Fe} / \mathrm{Fe}-\mathrm{MIL}-101$ as peroxidase mimetics to catalyze oxidation of the ABTS by $\mathrm{H}_{2} \mathrm{O}_{2}$.

\section{Methods}

\subsection{Chemicals and Instrumentation}

All commercial chemicals were used without further purification. Terephthalic acid $\left(\mathrm{H}_{2} \mathrm{BDC}, 99 \%\right)$, Ferric chloride hexahydrat $\left(\mathrm{FeCl}_{3} \cdot 6 \mathrm{H}_{2} \mathrm{O}\right.$, 99\%), ethanol (99.5\%), sodium borohydride $\left(\mathrm{NaBH}_{4}\right), \mathrm{NaOH}$, hydrogen peroxide $\left(\mathrm{H}_{2} \mathrm{O}_{2}\right)$ were purchased from Sigma-Aldrich.

2,2'-azino-bis(3-ethylbenzothiazoline-6-sulfonicacid) diammonium salt (ABTS) were obtained from BBI (Ontario,Canada). X-ray powder diffraction (XRD) experiments were conducted on a $\mathrm{D} / \mathrm{max}-3 \mathrm{~B}$ spectrometer with $\mathrm{Cu} \mathrm{Ka}$ radiation. Scans were made in the $2^{\theta}$ range $3^{\circ}-40^{\circ}$ with a scan rate of $10^{\circ} \mathrm{min}^{-1}$ (wide angle diffraction). Scanning electron microscopy (SEM) images of samples were obtained with a FEI Quanta 200FEG microscope. BET surface areas and pore volumes were measured through nitrogen adsorption/desorption measurements using a Micromeritics Tristar II surface area and porosity analyzer.

\subsection{Synthesis of Fe/Fe-MIL-101}

The Fe-MIL-101 is synthesized by hydrothermal method using p-dibenzoic acid 
as ligand iron as metal active center [24]. $\mathrm{FeCl}_{3} \cdot 6 \mathrm{H}_{2} \mathrm{O}(0.675 \mathrm{~g})$ was added slowly into DMF ( $15 \mathrm{~mL}$ ) solution, followed by adding $\mathrm{H}_{2} \mathrm{BDC}(0.206 \mathrm{~g})$. The mixture was under continuous mechanical stirring for $10 \mathrm{~min}$ at room temperature, and then transferred into a Teon-lined stainless steel autoclave and heated at $110^{\circ} \mathrm{C}$ for $20 \mathrm{~h}$. The resulting brown solid was separated from the reaction medium, and purified by using the hot ethanol $\left(70^{\circ} \mathrm{C}\right)$, the purification process was carried out several times, followed by drying in an oven $\left(70^{\circ} \mathrm{C}, 30 \mathrm{~min}\right)$. The particles were separated by centrifuging and washed with DMF and ethanol to remove any unreacted raw materials.

\subsection{Preparation of $1 \%$ Fe/Fe-MIL-101}

$\mathrm{FeCl}_{3} \cdot 6 \mathrm{H}_{2} \mathrm{O}(0.0195 \mathrm{~g})$ and Fe-MIL-101 (0.4 g) were dissolved in ethanol, stirred at room temperature for $1 \mathrm{~h}$, centrifuged and washed 3 times in ethanol and dried under vacuum at $80^{\circ} \mathrm{C}$ to obtain the product $1 . \mathrm{NaBH}_{4}(2 \mathrm{~mL}, 1.875$ $\mathrm{mg} / \mathrm{mL}$ ) solution was added dropwise to the solution of product 1 (product 1:150 mg, ethanol: $10 \mathrm{~mL}$, dichloromethane: $50 \mathrm{~mL}$ ), stirred at $0^{\circ} \mathrm{C}$ under nitrogen for $30 \mathrm{~min}$ and then stirred at room temperature for $30 \mathrm{~min}$. The precipitate was collected by centrifuging to obtain the product $1 \%$ Fe/Fe-MIL-101.

$3 \% \mathrm{Fe} / \mathrm{Fe}-\mathrm{MIL}-101,5 \% \mathrm{Fe} / \mathrm{Fe}-\mathrm{MIL}-101$, and $8 \% \mathrm{Fe} / \mathrm{Fe}-\mathrm{MIL}-101$ were prepared by changing the amount of $\mathrm{FeCl}_{3} \cdot 6 \mathrm{H}_{2} \mathrm{O}$ added.

\subsection{Peroxidase-Like Activity of 5\% Fe/Fe-MIL-101}

The effect of $\mathrm{pH}$, temperature, $\mathrm{H}_{2} \mathrm{O}_{2}$ concentration and ABTS concentration on the peroxidase-like activity of $5 \% \mathrm{Fe} / \mathrm{Fe}-\mathrm{MIL}-101$ was performed in a reaction volume of $3 \mathrm{~mL}$ of buffer solution. Buffers used in this experiment were acetate buffer ( $\mathrm{pH} 4.0-6.0)$ and borate buffer ( $\mathrm{pH} 8.0-10.0)$. The steady state kinetic assays of $5 \% \mathrm{Fe} / \mathrm{Fe}-\mathrm{MIL}-101$ were carried out by changing the concentration of ABTS at a fixed concentration of $\mathrm{H}_{2} \mathrm{O}_{2}$ or vice versa at $50^{\circ} \mathrm{C}$. After 5 minutes of reaction, the absorbance of the reaction solution was measured at a wavelength of $420 \mathrm{~nm}$ using a Shi-madzu UV-2450 spectrophotometer. The kinetic parameters were calculated based on the equation:

$$
v=V \max \left([S] /\left(K_{m}+[S]\right)\right)
$$

where $v$ is the initial velocity, $V_{\max }$ is the maximal velocity, $[S]$ is the concentration of the substrate, and $K_{m}$ is the Michaelis constant.

\section{Results and Discussion}

\subsection{The Characterization of Fe/Fe-MIL-101}

The X-ray diffraction (XRD) pattern of the as-synthesized Fe-MIL-101 is shown in Figure 1(a). The diffraction peaks all corresponded to the products synthesized in the literature [24] and generally consistent with the pattern calculated from the crystallographic data in this reference. Moreover the diffraction peaks position of obtained Fe/Fe-MIL-101 by different iron loadings are the same as Fe-MIL-101, but the intensity of the diffraction peaks are weaker than 


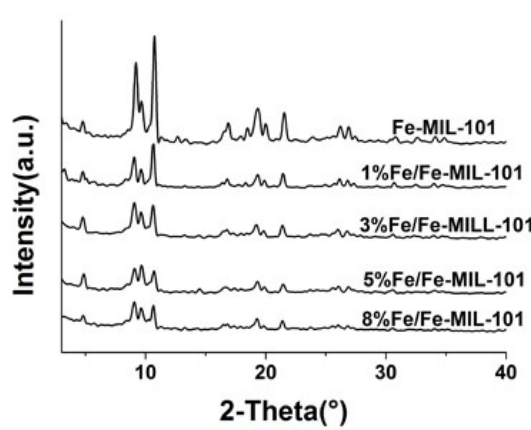

(a)

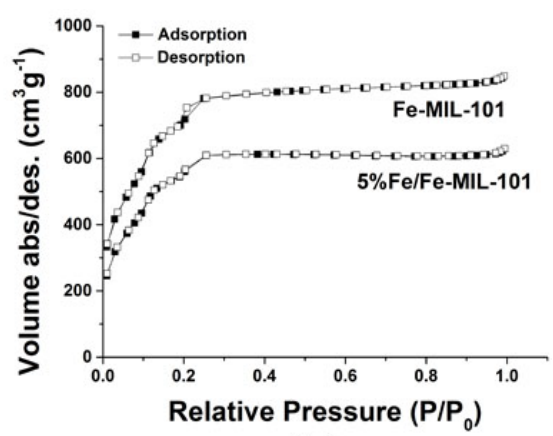

(b)

Figure 1. (a) XRD patterns of the Fe-MIL-101 and Fe/Fe-MIL-101. (b) $\mathrm{N}_{2}$ adsorption/desorption isotherm pore distribution of 5\% Fe/Fe-MIL-101 and Fe-MIL-101.

Fe-MIL-101. The adsorption - desorption isotherms of 5\% Fe/Fe-MIL-101 are of type I (Figure 1(b)), indicating the presence of a microporous network. Compared with Fe-MIL-101, the BET specific surface area of the experimentally synthesized 5\% Fe/Fe-MIL-101 material decreased from $2737 \mathrm{~m}^{2} / \mathrm{g}$ to $2148 \mathrm{~m}^{2} / \mathrm{g}$, and the pore volume decreased from $0.75 \mathrm{~cm}^{3} \cdot \mathrm{g}^{-1}$ to $0.51 \mathrm{~cm}^{3} \cdot \mathrm{g}^{-1}$, the average pore size decreased from $2.51 \mathrm{~nm}$ to $2.35 \mathrm{~nm}$, the reduction of specific surface area, pore size and pore volume probably due to the blockage of material pores by the loaded iron. SEM images show that $5 \% \mathrm{Fe} / \mathrm{Fe}-\mathrm{MIL}-101$ has a typical octahedron morphology like Fe-MIL-101 (Figure 2(a) and Figure 2(b)), but the surface is rough, and it is obvious that there are small solid iron particles on the surface. All of the results mentioned above confirmed that 5\% Fe/Fe-MIL-101 was successfully synthesized.

\subsection{Peroxidase-Like Activity of $1 \% \mathrm{Fe} / \mathrm{Fe}-\mathrm{MIL}-101$}

In order to study the peroxidase-like activity of $1 \% \mathrm{Fe} / \mathrm{Fe}-\mathrm{MIL}-101$, the conventional catalytic oxidation of the peroxidase substrate ABTS in the presence of $\mathrm{H}_{2} \mathrm{O}_{2}$ was tested. As shown in Figure 3, in the absence and presence of $\mathrm{H}_{2} \mathrm{O}_{2}$, which displayed a negligible absorption at the maximum absorbance of $420 \mathrm{~nm}$, indicating that ABTS could not be oxidized by $\mathrm{H}_{2} \mathrm{O}_{2}$ without any catalysts. In contrast, $1 \% \mathrm{Fe} / \mathrm{Fe}-\mathrm{MIL}-101$ could catalyze the oxidation of ABTS by $\mathrm{H}_{2} \mathrm{O}_{2}$ (Figure 3), with a maximum absorbance at $420 \mathrm{~nm}$, indicating that $1 \%$ $\mathrm{Fe} / \mathrm{Fe}-\mathrm{MIL}-10$ gave higher response and showed catalytic activity toward ABTS oxidation in the presence of $\mathrm{H}_{2} \mathrm{O}_{2}$.

Table 1 mainly compares the absorbance values of Fe/Fe-MIL-101 with iron loadings at load ratios $\mathrm{R}=0.01, \mathrm{R}=0.03$ and $\mathrm{R}=0.05, \mathrm{R}=0.08$, respectively. A significant effect of the load ratio on the absorbance values is visible, the absorbance value are growing with increasing load ratio $(R=0.01-0.05)$, however, the absorbance value is decreasing when the load ratio is increased to 0.08 . Since the absorbance value of 5\% Fe/Fe-MIL-101 was the largest, 5\% Fe/Fe-MIL-101 was selected as the experimental object in the next experiment.

The peroxidase-like catalytic activity of $5 \% \mathrm{Fe} / \mathrm{Fe}-\mathrm{MIL}-101$ was studied by 

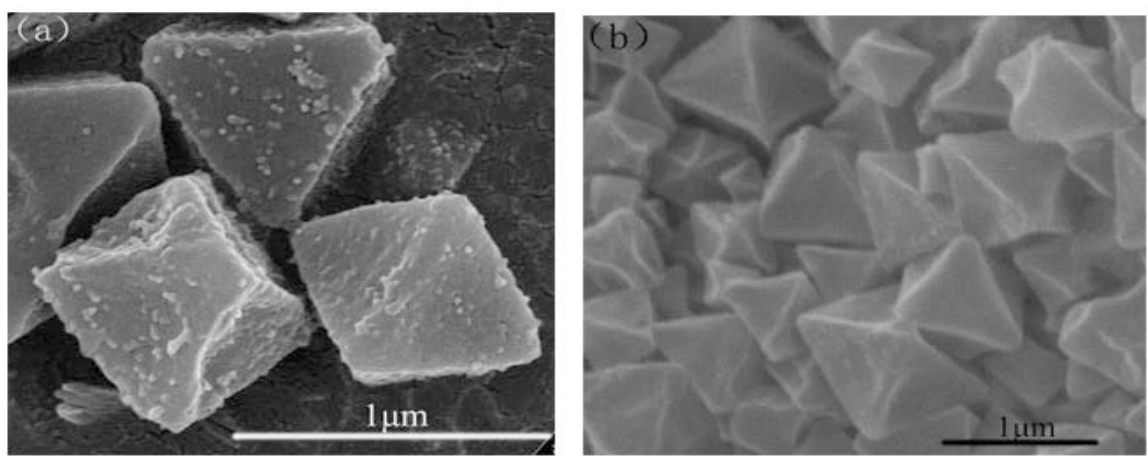

Figure 2. (a) SEM images of the 5\% Fe/Fe-MIL-101 and (b) Fe-MIL-101.

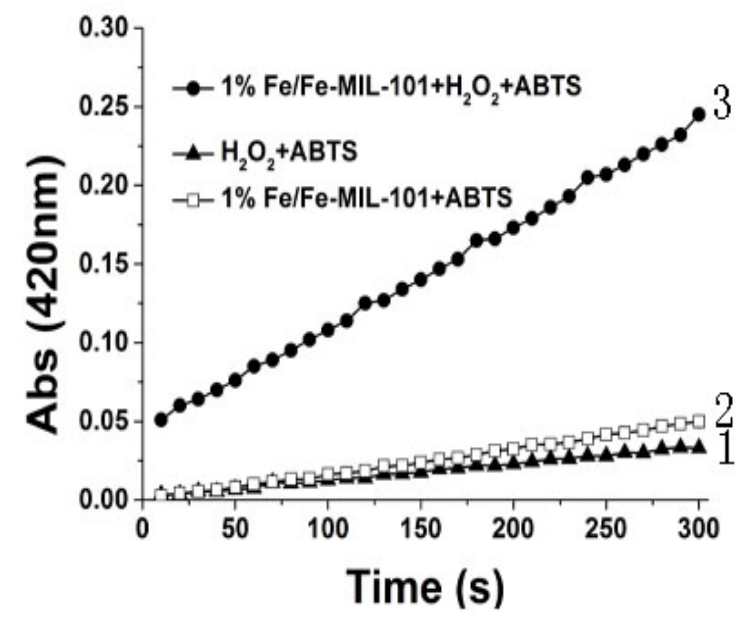

Figure 3. Time-dependent absorbance changes at 420 $\mathrm{nm}$ in the presence of (1) $\mathrm{H}_{2} \mathrm{O}_{2}$ and ABTS, (2) ABTS and $1 \% \mathrm{Fe} / \mathrm{Fe}-\mathrm{MIL}-101,(3) \mathrm{H}_{2} \mathrm{O}_{2}$ and ABTS and $1 \%$ $\mathrm{Fe} / \mathrm{Fe}-\mathrm{MIL}-101$.

Table 1. Comparison of absorbance values of different catalyst.

\begin{tabular}{ccccc}
\hline Catalysts & $1 \% \mathrm{Fe} / \mathrm{Fe}-\mathrm{MIL}-101$ & $3 \% \mathrm{Fe} / \mathrm{Fe}-\mathrm{MIL}-101$ & $5 \% \mathrm{Fe} / \mathrm{Fe}-\mathrm{MIL}-101$ & $8 \% \mathrm{Fe} / \mathrm{Fe}-\mathrm{MIL}-101$ \\
\hline $\begin{array}{c}\text { Absorbance } \\
\text { Values }\end{array}$ & 0.245 & 0.311 & 0.404 & 0.331 \\
\hline
\end{tabular}

selecting the substrates ABTS and $\mathrm{H}_{2} \mathrm{O}_{2}$ as a model reaction system. The peroxidase-like activity of $5 \% \mathrm{Fe} / \mathrm{Fe}-\mathrm{MIL}-101$ was measured at different $\mathrm{pH}$ (3.0-9.0) and various temperature $\left(30^{\circ} \mathrm{C}-50^{\circ} \mathrm{C}\right.$ ) (Figure $4(\mathrm{a})$ and Figure 4(b)). As can be seen from Figure 5, the $\mathrm{pH} 4.0$ and $45^{\circ} \mathrm{C}$ were the optimal reaction condition, which are very similar to the values for HRP [25].

\subsection{Kinetic Analysis}

We used steady-state kinetics to further study the peroxidase-like catalytic mechanism and kinetic parameters of 5\% Fe/Fe-MIL-101. The kinetic data was collected by changing the concentration of one substrate at a fixed concentration of the other substrate. Within the concentration range of TMB and $\mathrm{H}_{2} \mathrm{O}_{2}$ used, 
(a)

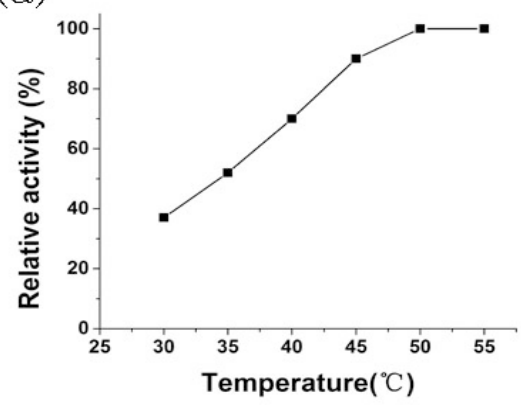

(b)

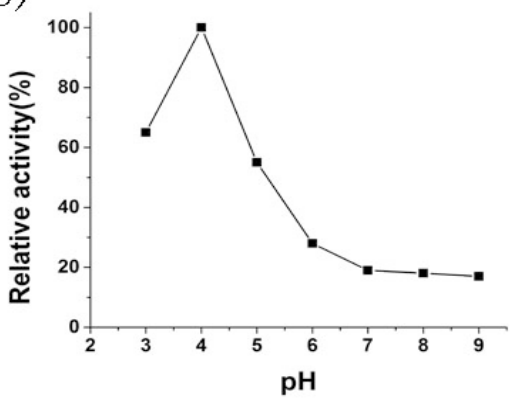

Figure 4. The peroxidase-like activity of the 5\% Fe/Fe-MIL-101 hybrid is dependent on the temperature (a) and $\mathrm{pH}(\mathrm{b})$.
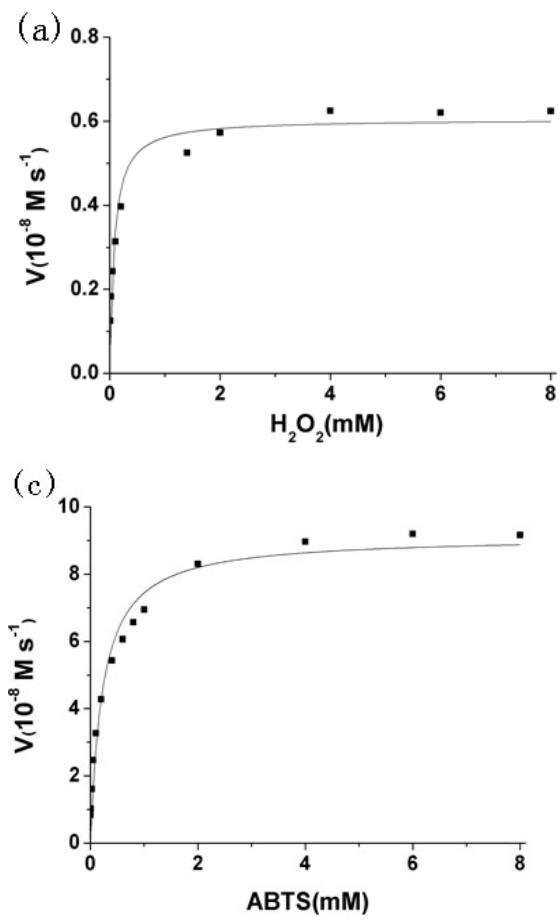

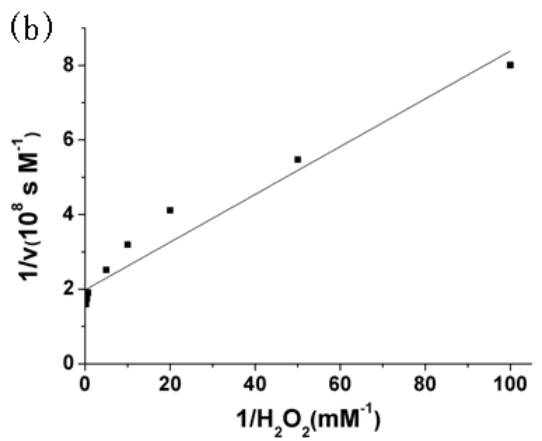

(d)

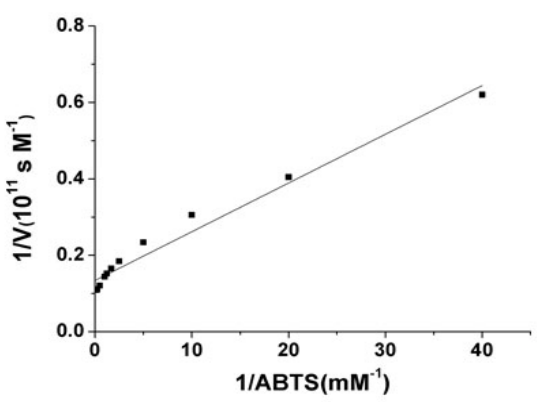

Figure 5. ((a) and (c)) Steady-state kinetic assays of 5\% Fe/Fe-MIL-101. (a) The concentration of TMB was fixed and the $\mathrm{H}_{2} \mathrm{O}_{2}$ concentration was varied in acetate buffer at $\mathrm{pH}$ 4.0 (b) double-reciprocal plots of the activity of 5\% Fe/Fe-MIL-101. (c) The concentration of $\mathrm{H}_{2} \mathrm{O}_{2}$ was fixed and the ABTS concentration was varied in acetate buffer at $\mathrm{pH}$ 4.0. (d) double-reciprocal plots of the activity of $5 \%$ Fe/Fe-MIL- 101.

typical Michaelis-Menten curves were observed (Figure 5). A Lineweaver-Burk plot can be obtained with a nearly linear relationship (Figure 5(b) and Figure 5(d)), from which important kinetic parameters can be derived (Table 2). The kinetic parameters, such as the Michaelis-Menten constant $\left(K_{m}\right)$ and maximum initial velocity ( $V_{\max }$ ) were from a Lineweaver-Burk plot. The Michaelis constant, $K_{m}$, the smaller the $K_{m}$ value, the stronger the affinity of the enzyme to the substrate, and the higher the catalytic activity of the enzyme. As shown in Table 2 , the $K_{m}$ value of $5 \% \mathrm{Fe} / \mathrm{Fe}-\mathrm{MIL}-101(0.095 \mathrm{mM})$ with ABTS as the substrate under the optimum conditions ( $20 \mathrm{mM}$ acetate buffer, $\mathrm{pH} 4.0$ ) was about 3-fold 
Table 2. Comparison of the Michaelis constant $\left(K_{m}\right)$ of 5\% Fe/Fe-MIL-101 and other enzyme mimics at $\mathrm{pH} 4.0$.

\begin{tabular}{ccccc}
\hline Catalysts & Substrates & $K_{m}(\mathrm{mM})$ & $V_{\max }\left(\mathrm{M} \cdot \mathrm{s}^{-1}\right)$ & Reference \\
\hline $5 \%$ Fe/Fe-MIL-101 & ABTS & 0.095 & $5.376 \times 10^{-11}$ & This work \\
5\% Fe/Fe-MIL-101 & $\mathrm{H}_{2} \mathrm{O}_{2}$ & 2.7 & $5.051 \times 10^{-11}$ & This work \\
Fe-MIL-101 & $\mathrm{ABTS}$ & 0.916 & $1.603 \times 10^{-11}$ & {$[26]$} \\
Fe-MIL-101 & $\mathrm{H}_{2} \mathrm{O}_{2}$ & 3.7 & $2.498 \times 10^{-11}$ & {$[26]$} \\
CuO NPs & $\mathrm{ABTS}$ & 10.28 & & {$[27]$} \\
CuO NPs & $\mathrm{H}_{2} \mathrm{O}_{2}$ & 120.3 & & {$[27]$} \\
$\mathrm{HRP}$ & $\mathrm{ABTS}_{\mathrm{H} P}$ & 0.319 & & {$[25]$} \\
$\mathrm{HRP}$ & $\mathrm{H}_{2} \mathrm{O}_{2}$ & 5.44 & & {$[25]$} \\
\hline
\end{tabular}

lower than HRP $(0.319 \mathrm{mM})$, and this value is about 108 times less than that of $\mathrm{CuO}$ NPs $\left(K_{m}=10.28 \mathrm{mM}\right)$ and about 10-fold lower than Fe-MIL-101 $(0.916$ $\mathrm{mM}$ ), indicating a much higher affinity for $\mathrm{H}_{2} \mathrm{O}_{2}$ than $\mathrm{HRP}$ and most of the peroxidase mimetics at $\mathrm{pH} 4.0$.

\section{Conclusion}

The present study demonstrates that the 5\% Fe/Fe-MIL-101 exhibited excellent peroxidase-like activity, catalyzing the oxidation of ABTS in the presence of $\mathrm{H}_{2} \mathrm{O}_{2}$. The Michaelis constant $\left(K_{m}\right)$ of $5 \% \mathrm{Fe} / \mathrm{Fe}-\mathrm{MIL}-101$ with ABTS as the substrate is about 10-fold smaller than Fe-MIL-101 and about 3-fold smaller than $\mathrm{HRP}$, and about 108 times less than that of $\mathrm{CuO} \mathrm{NPs}\left(K_{m}=10.28 \mathrm{mM}\right)$, indicating a much higher affinity for ABTS than HRP and most of the peroxidase mimetics. The above findings will open such catalytic systems for a variety of potential applications in biological systems in the future because of their ease of preparation, high activity and stability.

\section{Acknowledgements}

The authors thank the National Natural Science Foundation of China (81860532) and Key Research and Development Plan of Yunnan Province (2018BA065). The authors also thank the Industrialization Cultivation Project (2016CYH04), Scientific Research Fund of Department of Yunnan Education (2017ZZX223), the Program for Innovation Team of Yunnan Province and Key Laboratory of Advanced Materials for Wastewater Treatment of Kunming for financial support. The authors also thank Research Funding of Yunnan Provincial Department of Transportation (2017-438) and Yunnan Water Conservancy Science and Technology Plan of the Water Resources Department of Yunnan province and the Program for Science and Technology Projects of Yunnan Industrial of China Tobacco Industry CO., Ltd. (2015CP03, 2017539200370194, 2016539200340108) for financial support. 


\section{Conflicts of Interest}

The authors declare no conflicts of interest regarding the publication of this paper.

\section{References}

[1] Wulff, G. (2002) Enzyme-Like Catalysis by Molecularly Imprinted Polymers. Chemical Reviews, 102, 1-28. https://doi.org/10.1021/cr980039a

[2] Shoji, E. and Freund, M.S. (2002) Potentiometric Saccharide Detection Based on the pKa Changes of Poly (Aniline Boronic Acid). Journal of the American Chemical Society, 124, 12486-12493. https://doi.org/10.1021/ja0267371

[3] Marinescu, L.G. and Bols, M. (2010) Very High Rate Eenhancement of Benzyl Alcohol Oxidation by an Artificial Enzyme. Angewandte Chemie, 45, 4590-4593. https://doi.org/10.1002/anie.200600812

[4] Günter, W., Chong, B. and Ute, K. (2010) Soluble Single-Molecule Nanogels of Controlled Structure as a Matrix for Efficient Artificial Enzymes. Angewandte Chemie, 45, 2955-2958. https://doi.org/10.1002/anie.200503926

[5] Aissaoui, H., Bachmann, R., Schweiger, A. and Woggon, W.D. (1998) On the Origin of the Low-Spin Character of Cytochrome P450CAM in the Resting State-Investigations of Enzyme Models with Pulse Epr and Endor Spectroscopy. Angewandte Chemie International Edition, 37, 2998-3002. https://doi.org/10.1002/(SICI)1521-3773(19981116)37:21<2998::AID-ANIE2998>3.0 .CO;2-P

[6] Ghosh, M., Conroy, J.L. and Seto, C.T. (1999) Hydrolysis of Amides Catalyzed by 4-Heterocyclo Hexanones: Small Molecule Mimics of Serine Proteases. Angewandte Chemie International Edition, 38, 514-516. https://doi.org/10.1002/(SICI)1521-3773(19990215)38:4<514::AID-ANIE514>3.3.C $\underline{\mathrm{O} ; 2-\mathrm{A}}$

[7] Chen, K. and Jr., L.Q. (1999) Cis-Dihydroxylation of Olefins by a Non-Heme Iron Catalyst: A Functional Model for Rieske Dioxygenases. Angewandte Chemie International Edition, 38, 2227-2229.

https://doi.org/10.1002/(SICI)1521-3773(19990802)38:15<2227::AID-ANIE2227>3.0 .CO;2-B

[8] Molenveld, P., Engbersen, J.F.J. and Reinhoudt, D.N. (1999) Specific Rna Dinucleotide Cleavage by a Synthetic Calix[4] Arene-Based Trinuclear Metallo( II)-Phosphodiesterase. Angewandte Chemie International Edition, 38, 3189-3192.

https://doi.org/10.1002/(SICI)1521-3773(19991102)38:21<3189::AID-ANIE3189>3.0 .CO;2-X

[9] Wang, Q., Yang, Z., Zhang, X., Xiao, X., Chang, C.K. and Xu, B. (2010) A Supramolecular-Hydrogel-Eencapsulated Hemin as an Artificial Enzyme to Mimic Peroxidase. Angewandte Chemie, 46, 4285-4289. https://doi.org/10.1002/anie.200700404

[10] Fruk, L. and Niemeyer, C.M. (2010) Covalent Hemin-Dna Adducts for Generating a Novel Class of Artificial Heme Enzymes. Angewandte Chemie, 44, 2603-2606. https://doi.org/10.1002/anie.200462567

[11] Zhang, G. and Dasgupta, P.K. (1992) Hematin as a Peroxidase Substitute in Hydrogen Peroxide Determinations. Analytical Chemistry, 64, 517-522. https://doi.org/10.1021/ac00029a013

[12] Wang, Q., Liu, Z., Cai, R. and Gongxuan, L. (2002) Highly Sensitive Determination of Hydrogen Peroxide with Hemoglobin as Catalyst. Chinese Journal of Analytieal 
Chemistry, 30, 928-931.

[13] Liu, Z., Cai, R., Mao, L., Huang, H. and Ma, W. (1999) Highly Sensitive Spectrofluorimetric Determinationof Hydrogen Peroxide with $\beta$-Cyclodextrin-Hemin as Catalyst. Analyst, 124, 173-176. https://doi.org/10.1039/a807027j

[14] Bonarlaw, R.P. and Sanders, J.K.M. (2002) Polyol Recognition by a Steroid-Capped Porphyrin. Enhancement and Modulation of Misfit Guest Binding by Added Water or Methanol. Journal of the American Chemical Society, 117, 259-271. https://doi.org/10.1021/ja00106a029

[15] López-Serrano, A., Olivas, R.Z., Landaluze, J.S. and Cámara, C. (2013) Nanoparticles: A Global Vision. Characterization, Separation, and Quantification Methods. Potential Environmental and Health Impact. Analytical Methods, 6, 38. https://doi.org/10.1039/C3AY40517F

[16] Murray, L.J., Dincäf, M. and Long, J.R. (2009) Hydrogen Storage in Metal-Organic Frameworks. Chemical Society Reviews, 38, 1294-1314. https://doi.org/10.1039/b802256a

[17] Li, J.R., Sculley, J. and Zhou, H.C. (2012) Metal-Organic Frameworks for Separations. Chemical Reviews, 112, 869-932. https://doi.org/10.1021/cr200190s

[18] Lee, J.Y., Farha, O.K., Roberts, J., Scheidt, K.A., Nguyen, S.B.T. and Hupp, J.T. (2010) Cheminform Abstract: Metal-Organic Framework Materials as Catalysts. Cheminform, 40. https://doi.org/10.1002/chin.200933268

[19] Wang, J., Chen, D., Li, B., He, J., Duan, D., Shao, D., et al. (2016) Fe-MIL-101 Exhibits Selective Cytotoxicity and Inhibition of Angiogenesis in Ovarian Cancer Cells via Downregulation of MMP. Scientific Reports, 6, 26126.

https://doi.org/10.1038/srep26126

[20] Liu, Y.L., Zhao, X.J., Yang, X.X. and Li, Y.F. (2013) A Nanosized Metal-Organic Framework of Fe-MIL-88 $\mathrm{NH}_{2}$ as a Novel Peroxidase Mimic Used for Colorimetric Detection of Glucose. Analyst, 138, 4526-4531. https://doi.org/10.1039/c3an00560g

[21] Ai, L., Li, L., Zhang, C., Fu, J. and Jiang, J. (2013) MIL-53(Fe): A Metal-Organic Framework with Intrinsic Peroxidase-Like Catalytic Activity for Colorimetric Biosensing. Chemistry, 19, 15105-15108. https://doi.org/10.1002/chem.201303051

[22] Zhang, J.W., Zhang, H.T., Du, Z.Y., Wang, X., Yu, S.H. and Jiang, H.L. (2013) Water-Stable Metal-Organic Frameworks with Intrinsic Peroxidase-Like Catalytic Activity as a Colorimetric Biosensing Platform. Chemical Communications, 50, 1092-1094. https://doi.org/10.1039/C3CC48398C

[23] Li, B., Chen, D., Wang, J., Yan, Z., Jiang, L., Duan, D., et al. (2014) Mofzyme: Intrinsic Protease-Like Activity of Cu-MOF. Scientific Reports, 4, 6759. https://doi.org/10.1038/srep06759

[24] Kholdeeva, O., Skobelev, A., Kovalenko I.Y., Konstantin, A., et al. (2013) Solvent-Free Allylic Oxidation of Alkenes with O-2 Mediated by Fe- and Cr-MIL-101. Journal of Catalysis, 298, 61-69. https://doi.org/10.1016/j.jcat.2012.11.003

[25] Gao, L. and Jie, Z. (2009) Intrinsic Peroxidase-Like Activity of Ferromagnetic Nanoparticles and Its Application in Immunoassay and Environment Treatment. Journal of Biophysics, No. S1, 304-305.

[26] Zeng, Y.B. (2015) Study on the Properties of Fe-MIL-101 Simulated Peroxidase. Yunnan University, Kunming.

[27] Chen, J. (2010) Characteristics of Peroxide Mimic Enzymes of Nano-Copper Oxide and Its Application. Fujian Medical University, Fuzhou. 